\title{
Emotional labour, information literacy instruction, and the COVID-19 pandemic
}

\section{Karen Sobel}

Auraria Library, University of Colorado Denver, US

Lorraine Evans

Auraria Library, University of Colorado Denver, US

\section{Abstract}

The authors of this article, both instruction librarians, have researched the emotional labour that information literacy instruction librarians perform for several years. Several months into the COVID-19 pandemic, they discuss concepts of emotional labour among instruction librarians in that evolving context. They outline common aspects of emotional labour that manifest differently during the pandemic, compared to non-pandemic times. They identify and analyse new layers of emotional labour that many instruction librarians currently experience on top of their "normal" lives and emotional labour. They provide a brief overview of aspects of emotional labour that may be easier or lesser during the pandemic. The article concludes with a call for future research on these concepts, particularly using qualitative and mixedmethods research.

Keywords: emotional labour; information literacy instruction; library instruction; academic libraries; deep acting; surface acting. 


\section{Introduction}

Several years ago, we began researching the emotional labour that information literacy instruction librarians in higher education experience. Now, months into a global pandemic, these ideas seem a bit quaint at times. When we were putting together our first research and presentations on this topic, for example, our younger children went to neighborhood schools every day, and neither of us had ever worn a medical face mask. That said, much of the discussion we currently experience within our home department at the library (virtually, of course), and much of what we read through our professional connections on social media, deals with the emotions of working in academic libraries during the current pandemic.

In this article, we will discuss the emotional labour that academic librarians perform in the course of their work. We will compare emotional labour during the current global COVID-19 pandemic with labour performed during normal, non-pandemic times. We will introduce readers to two relevant concepts within the study of emotional labour (deep acting and surface acting) that will help readers to parse challenges with respect to internal response and intensity. We will outline ways in which the normal emotional labour of information literacy instruction manifests differently in the current pandemic, as well as new ways in which emotional labour overlays the labour that was already there. Later in the piece, we connect our work with psychologists' recent assertions that some individuals currently experience improved emotional states during the pandemic. Finally, we identify several aspects of emotional labour among instruction librarians that would benefit from qualitative and mixed methods research in the near future.

\section{Concepts related to emotional labour}

Several major concepts help to understand emotional labour in the context of information literacy instruction. The definition of emotional labour itself is not quite what many people imagine it to be. Emotional labour was defined as situational work in which we have to publicly display emotions that do not reflect our true feelings (Hochschild, 1983). While people 
often expand the concept of emotional labour to describe other challenges in the workplace and other settings (such as struggling with emotionally difficult patrons, or simply feeling exhausted after an occasional twelve-hour work day), the challenges generally connect with that feeling of having to hide one's true emotions and proceed with a smiling (or at least neutral) face.

Hochschild went on to describe two varieties of emotional labour: deep acting and surface acting. Deep acting refers to situations in which an individual believes in what they are doing, but still have to show some altered emotions (Hochschild, 1983, p. 33). For example, a librarian may feel preoccupied over their child's school situation on a given day and have to force a smile during an instruction session. However, the librarian still strongly believes in the value of the information literacy instruction. The emotion is genuine; they are just heightening it. Surface acting, by contrast, refers to situations in which an individual has to display truly false emotion (Hochschild, 1983, p. 35). For example, a librarian may have to participate in campus reopening plans that they feel are ineffective. When they have to unveil the plans to their colleagues while attempting to use a positive tone, they are surface acting.

The emotions that one feels while deep acting and surface acting are different, and their aftereffects also often differ. The following sections will apply these concepts in current contexts.

\section{Altered manifestations of emotional labour}

We have written about emotional labour among instruction librarians in more standard times (see, for example, Sobel \& Evans, 2021). Most importantly, our past work has put a good deal of emphasis on (a) minor power struggles between classroom faculty and instruction librarians, as the two parties co-design instructional content, and (b) communication challenges related to "silos" among units within a university. Based on our combined decades of experience in academic libraries, we have observed these to be two of the main sources of emotional labour during non-pandemic times. 
At present, the challenges seem to have shifted toward issues of distance rather than professional head-butting. In author Evans' recent experience-and related experiences that others at a range of institutions have shared with her-faculty often seem grateful for connection and support. They may, however, debate the modes by which support is offered. Both parties often have multiple directives that change rapidly over time, leading to frustration for each side. However, the overarching layer of gratitude is powerful. Once the current situation has progressed farther, it will be interesting to track librarians' perceptions of faculty attitudes and emotional responses toward librarians' work during the pandemic.

Issues related to "silos" within academic institutions have long provided challenges for academic librarians. Library leader Kaetrena Davis Kendrick (2017) has also identified ways in which silos within an institution lead to classroom faculty members' lack of knowledge about librarians' roles and abilities. This in turn leads to low morale among some academic librarians. It will be interesting to see how this changes during and after the pandemic. In our experience, faculty members are reaching out, requesting help, and expressing gratitudebut in many cases, librarians note that these are faculty members who have existing connections with the library. Those faculty members are likely to have at least some positive associations with librarians and experience with librarians' skills. They are also in a different frame of mind than usual. How will this shape connections and librarian morale in the future?

We have researched the emotional labour of academic librarians in recent years. Up to this point, our work has focused on non-pandemic scenarios, which seemed weighty enough without the added complexities of the present time. In a chapter written immediately prior to the pandemic (Sobel \& Evans, 2021), we discussed the challenges that face librarians as academic departments, as well as university committees, make major decisions without library representation. This situation continues to evolve during the COVID-19 pandemic. However, it appears to us that the traditional "silo" situation has been temporarily eclipsed by university-wide changes moving at a faster rate than many faculty and staff can follow. Groups making major decisions at this point are often so small and selective that many units and individual faculty may feel this sort of exclusion. It remains to be seen whether this emotional experience will change departments' and faculty members' future practices with relation to librarian inclusion. 


\section{New layers of emotional labour}

For many instruction librarians - and many university faculty members in general - the new layers of emotional labour involved in simply working and living day to day eclipse anything they may have experienced in the recent past. Many of us have new complications related to family: children "home schooling" in the house, concerns over adult children's living situations, greater than usual worry about aging parents' or chronically ill family members' health; the list goes on. Others face deep loneliness, boredom, and lack of daily conversation. The effort required to show up for work, even online, and to put on a pleasant, professional face despite all the challenges should not be underestimated.

Librarians also face concerns about their own health, and that of their family members, as they consider physically returning to campus. Understandings about modes of virus transmission change every day; public health guidelines change even more frequently than that. Universities' individual strategies and guidelines may change during the course of a single workday. This type of uncertainty, and the lack of established guidance, greatly adds to many people's emotional labour. We are at times expected to work with choices that we do not believe in (surface acting).

These are not our only levels of concern. Many library staff and librarians have been laid off from work or have experienced salary cuts or furloughs that may strain personal budgets (Peet, 2020). Some are also experiencing newly highlighted levels of inequity between staff and faculty at universities. Some institutions of higher education (such as ours) rank librarians as faculty, and others designate them as staff. Staff at some institutions face more layoffs than faculty, or orders to return to campus despite the situation being "unsafe" for faculty and students (Perry, 2020). These situations add the weight of working under conditions that one may disagree with, or in enforcing these conditions for others. They add a complex layer of emotional weight. 


\section{Improvements in emotional labour}

A few aspects of emotional labour may improve during the current situation. One example relevant to many academic librarians involves the fact that the concept of remote work is contentious in many workplaces. In the recent past, institutions may have frowned upon "working from home" for some categories of employees, including librarians. They have often made vague statements about accountability and measuring productivity. Librarians have long argued for the value of some quiet time working at home, in the face of prevailing attitudes that indicated a lack of professional trust by administration. This contributes to several layers of emotional labour: for example, struggling to work from the library when family needs, or the simple need for quiet workspace, contradicted that behavior; and the tension of implied distrust from administrators.

Now, by necessity, institutions have seen how truly productive librarians can be at home. They have also seen that productivity can be measured in terms of tasks and needs, rather than hours. This evidence provides some support for future change in policies regarding remote work during normal times. We hope that this begins a shift toward different guidelines for remote work, adding trust and removing a layer of emotional labour from librarians.

\section{Conclusions}

This is doubtless a time of increased emotional labour for most librarians. Handling increased health concerns, loneliness, family labour, and more, while maintaining professionalism is a huge challenge. We hope that, not too far in the future, the pandemic situation will resolve. We hope that the end of the pandemic will also bring some reexamination of workplace norms, such as considering greater openness to remote work. Librarians in the future will read this brief piece and imagine this strange time.

We encourage our colleagues to engage in research to gauge the effects of this time, and the changes that it has brought about. While this research is a stretch at the present time, it will be of great value to future librarians. 


\section{References}

Evans, L. and Sobel, K. (2021) 'Emotional labour of instruction librarians: Causes, impact and management', in Powell, C. and Ruffin, I. (eds.) The Emotional Self at Work in Higher Education. Hershey, Pennsylvania: IGI Global: pp. 104-119.

Hochschild, A. R. (1983) The managed heart: Commercialization of human feeling. Oakland, California: University of California Press.

Kendrick, K.D. (2017) 'The low morale experience of academic librarians: A phenomenological study', Journal of Library Administration, 57(8), pp. 846-878. Available at: $\underline{10.1080 / 01930826.2017 .1368325}$

Peet, L. (2020) 'Pandemic-caused austerity drives widespread furloughs, layoffs of library workers', Library Journal. Available at: https://www.libraryjournal.com/?detailStory=Pandemic-Caused-Austerity-DrivesWidespread-Furloughs-Layoffs-of-Library-Workers

Perry, D.M. (2020) 'What about the health of staff members?', Chronicle of Higher Education. Accessed at: https://www-chronicle-com /article/what-about-the-health-of-staffmembers/

\section{Author details}

Karen Sobel is an Associate Professor and Teaching \& Learning Librarian at the University of Colorado Denver in the United States. She also directs the Center for Faculty Development \& Advancement at the University of Colorado Denver. Her research interests focus on the motivations behind students' academic behaviors. 
Lorraine Evans is a Senior Instructor and the Teaching \& Learning Program Lead Librarian at the University of Colorado Denver in the United States. Lorraine's academic backgrounds are in psychology and library science; she combines them in the study of emotional labour among academic librarians. 